\title{
Correlation of Students' Perception after Project - Based Learning (Egg Drop Project) Intervention towards learning Physics
}

\author{
Jeffry Juan Rosales JR ${ }^{1}$, FauziahSulaiman ${ }^{2}$ \\ ${ }^{1}$ Faculty of Science and Natural Resources, Universiti Malaysia Sabah, Kota Kinabalu, Sabah, Malaysia \\ ${ }^{2}$ Faculty of Science and Natural Resources, Universiti Malaysia Sabah, Kota Kinabalu, Sabah, Malaysia
}

\begin{abstract}
The purpose of this research was to identifythe correlation of students' perception (i.e., personal interest, sense making and effort, real world connection and problem solving perception) in learning physics after the intervention of Project - Based Learning (PBL) (i.e., egg drop project). This research was conducted in Tuaran and Kota Maruduin Malaysia. A total of thirty- eight(38) form four students (i.e., 17 male and 21 female students) were used in the study. Data used in the study were collected using the Colorado Learning Attitude about Science Survey (CLASS) - personal interest, sense making, real world connection and problem solving general Category. Respondents were required to response to the survey instrument based on a five pointLikert scale after (post-survey)the implementation of PBL. Data collected were analysed using Statistical Package for Social Science Version 20.0 for windows (SPSS) to identify the correlation of students' perception based on the post-survey responses. Spearman's Rank-Order Correlation showed positive correlation between students' personal interest, making sense and effort, real world connection and problem solving perception that includes overall students.Therefore study revealed that through PBL-egg drop project, students could relate physics concepts; momentum, impulse and impulsive force into real life situations, engaged students' personal interest, sense making and effort, real world connection and problem solving perception and changed students' perception towards physics.
\end{abstract}

Keywords: Project-Based Learning, Physics Education, Egg Drop Project, Correlation, Perception

\section{I.INTRODUCTION}

Physics' popularity is not so high among secondary and high school's students (Holubova, 2008). Many students who enrolled in physics related course think and say, physics is difficult to learn and understand (Angell, Guttersrud, Henriksen, \&Isnes, 2004). The obvious factor makes physics difficult on the students' view are physics irrelevant to learn with the connection of everyday life and the more students learn about physics the more boring they will get (Erinosho, 2013). If students will not have a clear view what they learn and absorb, it will lead them to view physics as jumble of formulas and unrelated facts to memorise (Qian\&Alvermann, 2000).

This problem leads to a point where students feel that to learn physics is beyond their ability and capabilities to comprehend (Kovanen, 2011). Students' interest in physics needs to be sharpened and nurtured from early stage (Ornek, Robinson \&Haugan 2008). Students' interest and their effort are related to each other, when students have an interest towards physics, students' effort followed to learn more about physics (Net Industries, 2016). Meanwhile, students' interest also influences their abilities to solve problems (Khoo, 2015). Students have a meaningful learning towards physics when the problem solving strategy is involved real world connection problems (Bernkert, 2005).

\section{LITERATURE REVIEW}

When students come to the course with more personal interest, real world connection, sense making and effort are likely to have higher learning gain (Perkins, Adams, Pollock, Finkelstein \&Wieman, 2004). Hands on activities for physics in everyday life course give a positive effect towards students' personal interest, sense making and effort, real world connection and problem solving (Harlow, Landau \& Bailey, 2013). According to Perkins, Adams, Pollock, Finkelstein \&Wieman (2004) students' learning gain are correlated positively with students' personal interest, sense making and effort.Meanwhile, students' interest and students' problem solving skills towards physics influence to each other which, the higher students' interest towards physics makes higher students' ability to solve physics problems (Wenno, 2015).

In solving physics problems, knowledge and skills are related to each other to maintain a positive attitude towards physics (Erdemir, 2009). To be an expert problem solver, individual should turn problem solving into a habit which individual gain more experience and knowledge to feel more empowered when future 
problems arise (Allen, 2014). Furthermore, according to Trumper (2006), when students experience physics outside school their interest will be increased. Moreover, there is positive correlation between students' interest with students' real world connection and problem solving towards learning physics (Perkins, Gratny, Adams, Finkelstein \&Wieman, 2006). Students' conceptual knowledge about physics has a strong influence towards students' problem solving and achievement in physics (Carr \&Taasoobshirazi, 2009).

The implementation of Project - Based Learning (PBL) in physics related course has positively increase students' interest towards physics (Liu, 2014). PBL is adopted constructivist learning theory where students construct their own knowledge based on experience through actual projects (Holubova, 2008). Constructivism emphasises more on to construct knowledge rather than to transmit and record information given from another person (Applefield, Huber \&Moallem, 2001). PBL serves authentic learning chances and makes students to investigate various contain areas (Meyer \&Wurdinger, 2016). In addition, PBL provides opportunities for students to investigate and gather information towards meaningful questions as well as to think critically (Antic \&Spasic, 2012; Fauziah, 2011). After long investigation, students may answer the question on their own especially problems they have encountered earlier (Intel Research Program, 2007).

Effective PBL leads students to explore questions and important ideas as well as use their interest and information skills to explore, making conclusions and construct content through authentic and real world problems and issues (New York City Department of education, 2009). Students use a variety of tools to accomplish a project and create an artifact as evidence of what the students have learned (Holubova, 2008). Project needs to be planned properly and students need more time to accomplish the project and engage an effective learning (Muzzarelli, 2007).

In PBL, teacher plays an important role which teacher acts as a facilitator and provide hands-on activities that focuses on students' learning towards issues of problems and topic that not included in the textbook (Holubova, 2008). In addition, through PBL, teacher can plan learning activities that trigger students understanding in-depth towards essential ideas in the content which students have active learning and help them build their strengths and produce meaningful project that integrate their own abilities and interests (New York City Department of Education, 2009). Moreover, teacher needs to choose projects that can influence students' engagement to develop their interest and able to relate project with real life situations (Subramaniam, 2009).

Egg drop challenge is part of Drexel-SDP GK-12- activity in Drexel University, Philadelphia, USA to excel in Astronomy Module two which students act as a Mars Rover Engineers to drop and landed the rover on the planet from a spacecraft safely (Kusic\&Garbarine, 2008). According to Lost Angeles Unified School District, USA (2012), egg drop project helps students to enhance their understanding towards physics especially momentum and impulse concept. Hands-on projects such as egg drop project helps students to have better understanding in physics where students work in teams and build egg container using balsa wood sticks, glue and raw egg and drop the unit from a certain height and place on a target zone (Sridhara, 2013). This project is a great success as students can relate their understanding more about the concepts into real life situations which students free to apply their own skills and knowledge to design and build the egg's protector instead of taking order from manual book (Yusfi, 2014).

\section{Research Objectives}

The main objective of this study was:

- To identify the correlation between students' personal interest, sense making and effort, real world connection and problem solving before and after the implementation of PBL - egg drop project.

\section{RESEARCH METHODOLOGY}

This study employed a quantitative approach in its methodology and designs with pre-survey - postsurvey administered to the experimental group and none to the control group (Encyclopedia of Research Design, 2010). Sample collected from two schools situated in Tuaran and Kota Marudu District.Thirty - eight (38) Form Four (4) science students were involved in this study who took physics. As students were the respondents for this research, data could be extracted from two different places to measure the effectiveness of the implementation of PBL to improve students' perception towards physics. Researcher used the same methodology for both schools for this study.

\section{Survey Questionnaire}

According to Adams, Perkins, Podolefsky, Dubson, Finkelstein \&Wieman (2006), students' personal interest, sense making and effort, real world connection and problem solving perception inlearning physics can be measured by using The Colorado Learning Attitude about Science Survey (CLASS) - personal interest, sense making and effort, real world connection and problem solving general category. Each item statement was based on a five-pointLikert Scale as follows: Strongly Agree-5; Agree-4; Neutral-3; Disagree-2; and Strongly Disagree-1 (Adams, Perkins, Podolefsky, Dubson, Finkelstein \&Wieman, 2006). All statements passed the 
reliability and validity tests conducted by the University of Colorado Physics Education Research Group (Mistades, Reyes \&Scheiter, 2011). Each item statement was translated to Malay Language in this study. Before the intervention, a pilot test was conducted and the Cronbach's Alpha $(\alpha)$ coefficient value for each CLASS categoryshowed in Table 1. Result revealed that eachCLASS - categoryinstruments were reliable to be used in the data collection.

Table 1:Cronbach's Alpha $(\alpha)$ Coefficient Value for Each CLASS - Category

\begin{tabular}{|l|l|l|}
\hline CLASS - Category & Total Items & Cronbach's Alpha ( $\boldsymbol{\alpha})$ Coefficient \\
\hline Personal Interest & 6 & 0.750 \\
\hline Sense Making and Effort & 7 & 0.741 \\
\hline Real World Connection & 4 & 0.746 \\
\hline Problem Solving General & 8 & 0.804 \\
\hline
\end{tabular}

\section{Implementation of Project-Based Learning (Egg Drop Project)}

Students worked in a group project where each group consisted of three (3) or four (4) students. Students relate the physics concepts within the physics curriculum content namely as momentum, impulsive and impulsive force to build an egg protector by using the fundamental materials such as toothpicks, superglues and a raw egg provided by the facilitator. Each group was given two weeks to design and build the egg protector, discuss project-related issues and questions among group members and the facilitator. At the end of the twoweeks, students present their best model of the project and egg drop launching session was conducted from the two-level of building block. Each group need to make sure the raw egg not break after landed on the ground.

\section{RESULTS AND DISCUSSION}

Correlation between Overall Students' Personal Interest, Sense Making and Effort, Real World Connection and Problem Solving Perception

According to Dallal (2012), when number of samples was small, nonparametric correlation need to be done to identify monotonic relationship between two variables. In this study, Spearman's Rank - Order Correlation was used to identify the relationship between overall students' personal interest, sense making and effort, real world connection and problem solving perception for both schools in total. Data were used from each CLASS - category'spost-survey. Statistical Package for Social Science Version 20.0 for windows (SPSS) was used to analyse the correlation between each variables.According to Mukaka (2012), the interpretation of Spearman's coefficient $(\rho)$ varies in each value which are very strong positive correlation (0.90 to 1.00$)$, strong positive correlation $(0.70$ to 0.90$)$, moderate positive correlation $(0.50$ to 0.70$)$, weak positive correlation $(0.30$ to 0.50$)$ and no significant correlation (0.00 to 0.30$)$.

Referring to the Table 2 below, it showed that there was significance strong positive correlation on overall students' personal interest $(\rho=0.733, p=0.000)$ with overall students' sense making and effort. Meanwhile, overall students' personal interest showed significance strong positive correlation $(\rho=0.896, p=$ 0.000 ) with overall students' real world connection. Overall students' personal interest showed that there was significance moderate positive correlation $(\rho=0.668, p=0.000)$ with overall students' problem solving perception. Meanwhile, overall students' sense making and effort showed significance strong positive correlation $(\rho=0.710, p=0.000)$ with overall students' real world connection. Moreover, overall students' sense making and effort showed that there was significance strong positive correlation $(\rho=0.713, p=0.000)$ with overall students' problem solving perception. Overall students' real world connection showed that there was significance moderate positive correlation $(\rho=0.652, p=0.000)$ with overall students' problem solving perception.

Table 2:Correlation between Overall Students' Personal Interest, Sense Making and Effort, Real World Connection and Problem Solving perception

\begin{tabular}{|l|l|l|l|l|l|}
\hline Variables & PI & SME & RWC & PS \\
\hline \multirow{4}{*}{ PI } & Correlation Coefficient $(\rho)$ & 1 & $0.733^{* *}$ & $0.896^{* *}$ & $0.668^{* *}$ \\
\cline { 2 - 6 } & Sig. (2-tailed) & & 0.000 & 0.000 & 0.000 \\
\cline { 2 - 6 } & $\mathrm{N}$ & 38 & 38 & 38 & 38 \\
\hline \multirow{4}{*}{ SME } & Correlation Coefficient $(\rho)$ & $0.733^{* *}$ & 1 & $0.710^{* *}$ & $0.713^{* *}$ \\
\cline { 2 - 6 } & Sig. (2-tailed) & 0.000 & & 0.000 & 0.000 \\
\cline { 2 - 6 } & $\mathrm{N}$ & 38 & 38 & 38 & 38 \\
\hline \multirow{4}{*}{ RWC } & Correlation Coefficient $(\rho)$ & $0.896^{* *}$ & $0.710^{* *}$ & 1 & $0.652^{* *}$ \\
\cline { 2 - 6 } & Sig. (2-tailed) & 0.000 & 0.000 & & 0.000 \\
\cline { 2 - 6 } & $\mathrm{N}$ & 38 & 38 & 38 & 38 \\
\hline
\end{tabular}


Correlation of Students' Perception after Project - Based Learning (Egg Drop Project) Intervention..

\begin{tabular}{|l|l|l|l|l|l|}
\hline \multirow{4}{*}{ PS } & Correlation Coefficient $(\rho)$ & $0.668^{* *}$ & $0.713^{* *}$ & $0.652^{* *}$ & 1 \\
\cline { 2 - 6 } & Sig. (2-tailed) & 0.000 & 0.000 & 0.000 & \\
\cline { 2 - 6 } & $\mathrm{N}$ & 38 & 38 & 38 & 38 \\
\hline$* *$ Correlation is significant at the 0.01 level (2-tailed).
\end{tabular}

$P I=$ Personal Interest $;$ SME = Sense Making and Effort; $R W C=$ Real World Connection; PS = Problem Solving Perception

Findings from this study show that PBL gives positive effect on students' perception towards learning physics after four (4) weeks of intervention. According to Perkins, Adams, Pollock, Finkelstein \&Wieman (2004), there is positive correlation between students' personal interest, sense making and effort with students' learning gain towards introductory physics. But, there is no correlation between students' real world connection with students' learning gain towards introductory physics. In addition, when students come to the course with more personal interest, real world connection, sense making and effort are likely to have higher learning gain. Meanwhile, according to Wenno (2015), there is positive correlation between students' interest and students' problem solving skills towards physics which shows that the higher students' interest towards physics makes higher students' ability to solve physics problems. Furthermore, according to Trumper (2006), there is positive correlation between students' interest and students to experience physics outside school. Moreover, according to Perkins, Gratny, Adams, Finkelstein \&Wieman (2006), there is positive correlation between students' interest with students' real world connection and problem solving towards learning physics.

\section{CONCLUSION}

The correlation of students' perception based on Colorado Learning Attitude about Science Survey (CLASS) post-surveyresults in each category have reflected a strong agreement that implementation of ProjectBased Learning (PBL) can influence positively towards students personal interest, sense making and effort, real world connection and problem solving perceptionto learn physics. Projects came out with the questions that sometimes cannot be solved by rote learning as students engage in an active role. Moreover, projects have served to bridge classroom learning with the real-life applications. Through PBL, students have a clear understanding with the physics concepts they learned in class and indirectly can change their perception towards physics into more positive one and able to connect physics concepts into real life situations.

[1] Adams, W. K., Perkins, K. K., Podolefsky, N. S., Dubson, M., Finkelstein, N. D., \&Wieman, C. E. (2006). New instrument for measuring student beliefs about physics and learning physics: The Colorado Learning Attitudes about Science Survey. Physical Review Special Topics - Physics Education Research, 2(1), 1-14. http://doi.org/10.1103/PhysRevSTPER.2.010101

[2] Allen, Debbie (August 15, 2014) 5 Ways To Hone Your Problem-Solving Abilities And Become An Expert In Your Field (Retrieved Mac 16, 2016) http://www.fastcompany.com/3034396/5-ways-tohone-your-problem-solving-abilities-and-become-an-expert-in-your-field

[3] Amy P. Muzzarelli, The Effect of Implementing Project-based Education in High SchoolPhysics: File Folder Bridge Engineering: Digital Commons, Michigan Technological University, 2007.

[4] Angell C, Guttersrud $\varnothing$, Henriksen E K and Isnes A 2004 Physics: frightful, but fun. Pupils'and teachers' view of physics and physicsteachingSci. Educ.88683-706

[5] Antic, Z., \&Spasic D. (2012).PROJECT-BASED LEARNING IN ENGLISH FOR MEDICINE, (8).http://doi.org/10.5633/amm.2012.0210

[6] DaraKusic\& Elaine Garbarine (2008) Drexel University GK - 12 program, egg drop activityhttp://gk12.coe.drexel.edu/modules/doc/Dara_Kusic/Astronomy_05_egg_drop_competition_act ivity.pdf (Retrieved February 20, 2016)

[7] Encyclopedia of Research Design. 2010. Pretest-Posttest Design.In Encyclopedia of Research Design. SAGE RESEARCH METHODS, pp.1087 - 1092

[8] Erdemir, N. (2009). Determining students' attitude towards physics through problem-solving strategy.Asia-Pacific Forum on Science Learning and Teaching, 10(2), 1-19.

[9] Erinosho, S. Y. (2013). How Do Students Perceive the Difficulty of Physics in Secondary School? An Exploratory Study in Nigeria, 3(3), 1510-1515. http://doi.org/10.1145/2212776.2223799

[10] FundaOrnek: Balikesir University, Balikesir, Turkey. William R. Robinson \& Mark P. Haugan: Purdue University, West Lafayette,IN, USA. What makes physics difficult? International Journal of Environmental \& Science Education, 2008, 3 (1), 30 - 34, ISSN 1306 - 3065 IJESE from Australia

[11] Gerard E. Dallal, (May 5, 2012, 10:52:36 am). Nonparametric Statistics (Retrieved April 16, 2016) http://www.jerrydallal.com/lhsp/npar.htm 
[12] Harlow, J. J. B., Landau, R., \& Bailey, D. C. (2014). The Effects of Physics Breadth Courses on Student Attitudes about Science, 70(1), 7-10. Theme Issue: Physics Education (Vol.70 Issue 2, 2014) http://www.cap.ca/en/publications/physics-canada-pic/issue/70/2

[13] Holubova, R. (2008). Effective teaching methods - Project-based learning in physics.US-China Education Review, 5(12), 27-36.

[14] Intel Research Program (2007). Designing Effective Projects : Characteristics of Projects Benefits of Project-Based Learning Overview of Project-Based Learning Benefits of Project-Based Learning.Education, 1-4.

[15] James, M. Applefield, Richard Huber \&MahnazMoallem(2001). Constructivism In Theory And Practice: Toward A Better Understanding. Watson School of Education.The University of North Carolina at Wilmington http://doi.org/10.1007/s13398-014-0173-7.2

[16] Khoo, E. W. (2015). Research Review: Stewardship in the context of public sector leadership.Civil Service College.

[17] Kovanen, A. (2011). Where are we after 30 years of physics education research ?, (2010).

[18] Liu, S. (2014).Implementing Project-Based Learning in Physics and Statics Courses.121st ASEE Annual Conference \&Exposion, (June 15-18, 2014).

[19] Lost Angeles Unified School District, USA, (2012) Physics:Idea, B., \& Generation, N. (n.d.). Intro to Momentum Culminating Activity - Car Safety Engineering.

[20] Meyer, K., \&Wurdinger, S. (2016). Students 'Perceptions of Life Skill Development in Project-Based Learning Schools, 2(1), 91-114. http://doi.org/10.5296/jei.v2i1.8933

[21] Mistades.V., Reyes. R.D \&Scheiter.. (2011). Transformative Learning: Shifts in Students 'Attitudes toward Physics Measured with the Colorado Learning Attitudes about Science Survey, 1(7), 45-52.

[22] Mukaka, M. M. (2012). Statistics Corner: A guide to appropriate use of Correlation coefficient in medical research, 24(September), 69-71.

[23] Net Industries (2016) Effort and Interest - Effort, Interest, Effort and Interest (Retrieved March 20, 2016) http://education.stateuniversity.com/pages/1946/Effort-Interest.html

[24] New York City Department of Education. (2009). Project-Based Learning: Inspiring Middle School Students to Engage in Deep and Active Learning. Learning.

[25] Perkins, K. K., Adams, W. K., Pollock, S. J., Finkelstein, N. D., \&Wieman, C. E. (2004). Correlating Student Beliefs With Student Learning Using The Colorado Learning Attitudes about Science Survey, 6-9. Department of Physics, University of Colorado, Boulder, CO 80309

[26] Perkins, K. K., Gratny, M. M., Adams, W. K., Finkelstein, N. D., \&Wieman, C. E. (2006). Towards characterizing the relationship between students' interest in and their beliefs about physics. AIP Conference Proceedings, 818, 137-140. http://doi.org/10.1063/1.2177042

[27] Qian, G., \&Alvermann, D. (2000) Relationship between epistemological beliefs and conceptualchange learning. Reading and Writing Quarterly: Overcoming Learning Difficulties, 16, 59-74.

[28] Sridhara, B. S. (2013). Course-related undergraduate projects for dynamics.ASEE Annual Conference and Exposition, Conference Proceedings. Retrieved from http://www.scopus.com/inward/record.url?eid=2-s2.0-

84884338951\&partnerID=40\&md5=1d75365d4d3521bede84853f079c4c3d

[29] Subramaniam, P. R. (2009). Motivational Effects of Interest on Student Engagement and Learning in Physical Education : A Review. Int J Phys Education, 46(2), 11-20.

[30] Sulaiman, Fauziah. (2011). CRITICAL THINKING IN A PROBLEM-BASED LEARNING ONLINE.International Malaysian Educational Technology, Kuantan Pahang; online learning; http://eprints.ums.edu.my/8658/1/cp0000000084.pdf (Retrieved May 15, 2016)

[31] Sylvia Bernkert (2005) Conversation and Context in Physics Education. 1(13). Institution: Umeå universitetS-901 87 Umeå Swedenhttp://hdl.handle.net/2077/18144

[32] Taasoobshirazi, G., \& Carr, M. (2009). A Structural Equation Model of Expertise in College Physics, 101(3), 630-643. http://doi.org/10.1037/a0014557

[33] Trumper, R. (2006).Factors affecting junior high school students' interest in physics.Journal of Science Education and Technology, 15(1), 47-58. http://doi.org/10.1007/s10956-006-03556

[34] Wenno, I. H. (2015). The Correlation Study of Interest at Physics and Knowledge of Mathematics Basic Concepts towards the Ability to Solve Physics Problems of 7th Grade Students at Junior High School in Ambon Maluku Province , Indonesia, 2015.

[35] Yusfi . Md. Yusop (2014). International Journal of Aerospace Aviatioan\& Astronautics Volume 1, Edition III, January 2014Igarss 2014, (1), page 15 - 23 